\title{
About A New Complex Method of Climates Reconstruction and Forecasting of Climate Changes in the Future
}

\author{
Valentina V. Ukraintseva \\ V. L. Komarov Botanical Institute of Russian Academy of Sciences, Saint-Petersburg 397022, Russia
}

Received: January 15, 2015 / Accepted: January 25, 2015 / Published: February 25, 2015.

\begin{abstract}
This paper deals with a new integrated method of reconstruction and forecasting of climatic changes in future. The method is based on proxy data pollen-spore analysis method, ${ }^{14} \mathrm{C}$ analysis method, nowadays meteorological data, and data about of solar activity expressed in numbers of W (Wolf). Here we present the results of investigation of sediments of the 2nd Fomich River terrace, Taymyr Peninsula, Russia. The formation of the peat bog started $10500 \pm 140$ years BP and continued during the entire Holocene. The pollen analysis of the sediment samples of the 2nd Fomich River terrace and the analysis of surface samples from a larch forest, typical of this region, reveals two phytochrones: both climatically preconditioned - tundra phytochrone $\left(\mathrm{I}_{1-4}\right)$ and forest phytochrone $\left(\mathrm{II}_{1-4}\right)$. The techniques of reconstruction and forecasting of basic elements of climate are presented and discussed in details.
\end{abstract}

Key words: Holocene, pollen analysis, ${ }^{14} \mathrm{C}$ analysis, fossil and recent pollen-spore spectra (pollen-spore spectra), SI (Similarity index), basic elements of climate, solar activity, Wolf's number (W), forecasting of climate changes.

\section{Introduction}

The forecast of climatic changes in the future, in the near and in the far, is one of the most significant scientific issues of today. A lot of scientific teams and Inter-Governmental commissions of various countries are working on this issue [1]. This issue is directly connected with the issue of climatic changes reconstruction, since a reliable forecast of any phenomenon or event can only be made in the case if there is an idea how this or that phenomenon has developed in the past and in which state this one is today.

It is rather well known that the data of the pollen analysis method are very widely used for the reconstruction of climates of past. The method is based on the actuality principle: "There is only one fact in the pollen analysis that always holds true: a pollen grain of a plant species came from of specimen

Corresponding author: Valentina V. Ukraintseva, Dr., research fileds: biology and paleogeography. E-mail: valentina.ukraintseva@gmail.com. of that species" [2]. There is one more fact that always holds true too- - the fact that the pollen and spore of plants, settling on the surface of the Earth, form SPS (pollen-spore spectra). What is a pollen-spore spectrum? This notion is still interpreted in various works rather differently. The most exact definition, with my point of view, was given by Grichuk and Zaklinskaya [3]: "The pollen-sore spectrum is understood as a totality of pollen and spores of plants, both falling on the today's surface-soil of the Earth and detected in the fossil state, expressed in the form of a percentage ratio of the components".

It is recognized that SPS of contemporary surface-soil samples is formed during 50 years or so and reflects the vegetation's composition of the zonal and (or) local levels of this or that region. The predominant vegetation cover of any of the Earth's regions is a reflection of natural factors, among which the climate plays a decisive role. The notion of the climate as a leading natural factor, determining the distribution of vegetation on the Earth, is very old, but 
at the same time it is recognized in a lot of contemporary works on phytogeography [4-6] and many others. We have accepted this idea also for the development of an absolutely new method of reconstruction of climates of the past.

According to Borisov [7] "the climate's changes are understood as the replacement of one climate type by another; changes inside one type are fluctuations". At the same time the climate, as a component of the geographical environment, is understood as a multi-year state of the atmosphere, including the weather conditions, formed during the continuous process of its interaction with all other geographical factors and also preconditioned by the human activity. At the present time one uses, in order to reconstruct the climates of the past on the basis of pollen analysis data, the paleofloristic method of Iversen-Grichuk [8], the zonal method and a number of mathematical methods [10].

The new method of climate reconstruction, which we have developed, is based on the zonal principle too. Its cornerstone is the use of the SI (Similarity Indices), which are calculated for taxa of the zonal level-“General composition", of dominant and co-dominant plants in the pollen-spore spectra of sediments of any genesis and age. Here it must be noted that the notion of "General composition" of pollen-spore spectra, introduced in the practice of the pollen analysis by Grichuk and Zaklinskaya [3], is an integral notion. This is a fundamental notion of biogeographical level, which is of primary importance during the reconstruction of zonal types of vegetation and landscapes, their evolution in time and in space and, undoubtedly, also during the reconstruction of climates of the past. It is the "General composition" of pollen-spore spectra, both recent and fossil, that reflects the zonal structure of vegetative communities. However, our colleagues from an abroad country practically do not use this very important notion.

A connection between the composition of fossil SPS and the composition of SPS of contemporary surface-soil samples follows from the above-given key definition of the pollen-spore spectrum. It appears that this connection can be expressed by means of the criterion, which has been established by author and which is called the SI [9]. The introduced index helps to make a reliable correlation of fossil SPS on the zonal and the phytoceonotic levels. The possibility to express the connection, which exists between the components of the contemporary vegetative cover and the components of the vegetative cover of the past, and in consequence also the climate of the past in any of the studied regions, can be realized through the SI.

\section{Material}

We present here the new complex method of reconstruction of climates of the past and a forecasting of climatic changes in future based on:

(1) pollen-spore analysis data;

(2) ${ }^{14} \mathrm{C}$ analysis data;

(3) recent meteorological data;

(4) Sun activity data expressed in a numbers of Wolf's units (Max W, Min W).

\section{Methods}

The following procedure is to be used during the reconstruction of climates of the past on the basis of the pollen analysis data.

(1) The "General composition" of the fossil SPS and the "General composition" of the SPS of recent surface-soil samples are to be divided into four groups, corresponding to the four groups of plants' life forms: (a) trees' pollen; (b) shrub' and small shrubs' pollen; (c) grasses' and dwarf shrubs' pollen (Cassiope, Dryas, Vaccinium and other dwarf shrubs); (d) spores of Bryophyta and Pteridophyta plants.

(2) Dominants and co-dominants in the composition of the fossil SPS and in the composition of the SPS of surface-soil samples are to be detected.

(3) The similarity indices for the above-mentioned four groups of pollen and spores of plants of the "General composition" and for dominants and 
co-dominants are to be calculated.

The similarity indices are calculated under the following formula:

$$
\mathrm{X} / \mathrm{Y}=\mathrm{SI}
$$

where, $\mathrm{X}$ is the pollen and spores content of any taxon in the composition of the SPS of a fossil sample expressed in percentages; $\mathrm{Y}$ is the pollen and spores content of the same taxon in the composition of the recent SPS expressed in percentages; SI is the Similarity Index [9].

The SI can be calculated for any component of fossil SPS. However, this index can only be obtained if it is a conjugated study of fossil samples and recent soil samples. The calculation method for the SI is clearly demonstrated data of Table 1.

(4) The region of joint growth of dominant and co-dominant plants, detected in the composition of the fossil SPS, is to be established with the method of area grams. Such region is the region of analogy for the fossil tax a of the zonal and phytoceonotic levels. It is correct to use the data of a meteorological station, located in the region of analogy, or the data of a meteorological station (s) nearest to it, obtained by means of interpolation, for the reconstruction of climatic elements in the studied region.

(5) It is advisable to use the following climatic elements during the reconstruction:

The average July temperature or August temperature for Arctic and mountainous regions;

The average January temperature;

The average annual temperature;

The sum of temperatures above null degrees $C$;

The amount of precipitation per annum;

The amount of precipitation during the period with the temperatures above null degrees Celsius expressed in percentage of the amount of precipitation per annum.

The sum of temperatures for the entire period with an average daily temperature above $0{ }^{\circ} \mathrm{C}$ is to be obtained by means of addition of cumulative sums of temperatures in separate full and fractional months within this period [10]. (The Reference Book of Climate..., 1966)]. The total of temperatures is an integral characteristic of a temperature mode, which reflects the resources of warmth preconditioned by a radioactive balance of any territory.

The reconstruction of the climatic elements, which were mentioned above, is done under the following formula:

$$
r_{n}=R_{n} \times S I_{n}
$$

where, $r_{n}$ is any of the above-mentioned climatic elements, reconstructed for the studied region; $R_{n}$ is any of the above-mentioned elements of the contemporary climate in the region-analogy; $S_{1-4}$ is the similarity indices of the zonal level, which are calculated for the elements of the general composition.

Table 1 Similarity Indices calculated for the tree pollen group in the composition of pollen-spore spectra of the sediments

\begin{tabular}{|c|c|c|c|c|c|c|c|c|c|}
\hline \multirow{3}{*}{ Sample, lithology } & \multicolumn{9}{|c|}{ Pollen } \\
\hline & \multicolumn{3}{|c|}{ Trees } & \multicolumn{3}{|c|}{ Larix gmelinii } & \multicolumn{3}{|c|}{ Long distance blown pollen of trees } \\
\hline & Contents & $\%$ & SI & Contents & $\%$ & SI & Contents & $\%$ & SI \\
\hline 1, surface-soil sample & 78 & 18.6 & 1 & 53 & 12.6 & 1 & 25 & 5.9 & 1 \\
\hline 2 , peat & 91 & 16.0 & 0.86 & 68 & 12.0 & 0.95 & 23 & 4.0 & 0.68 \\
\hline 3 , peat & 63 & 20.0 & 1.1 & 42 & 13.4 & 1.06 & 21 & 6.6 & 1.1 \\
\hline 4 , peat & 60 & 13.4 & 0.72 & 50 & 11.2 & 0.88 & 10 & 2.2 & 0.37 \\
\hline 5 , peat & 18 & 4.6 & 0.25 & 14 & 3.6 & 0.28 & 4 & 1.0 & 0.17 \\
\hline 6 , peat & 14 & 4.3 & 0.23 & 12 & 3.7 & 0.29 & 2 & 0.6 & 0.10 \\
\hline 7 , peat & 29 & 5.9 & 0.32 & 28 & 5.7 & 0.45 & 1 & 0.2 & 0.03 \\
\hline 8 , peat & 20 & 4.2 & 0.22 & 19 & 4.0 & 0.32 & 1 & 0.2 & 0.03 \\
\hline 9 , loamy sand & 31 & 5.9 & 0.31 & 17 & 3.3 & 0.26 & 14 & 2.6 & 0.44 \\
\hline
\end{tabular}
from above-the-flood-plain terrace 2 of the Fomich River, south-east Taymyr Peninsula, Russia [8, 9]. 
The above-mentioned climatic elements and similarity indices, which are used during the reconstruction, are designated for their usability during calculations as follows:

$\mathrm{R}_{1}$ - average July temperature $\left({ }^{\circ} \mathrm{C}\right)$;

$\mathrm{R}_{2}$ - average January temperature $\left({ }^{\circ} \mathrm{C}\right)$;

$\mathrm{R}_{3}$ - average annual temperature $\left({ }^{\circ} \mathrm{C}\right)$;

$\mathrm{R}_{4}$ - sum of air temperatures above $0{ }^{\circ} \mathrm{C}$;

$\mathrm{R}_{5}$ - amount of precipitation per annum ( $\mathrm{mm}$ );

$\mathrm{R}_{6}$ - amount of precipitation during the period with the temperatures above $0{ }^{\circ} \mathrm{C}$, expressed in percentage from the amount of precipitation per annum;

$\mathrm{SI}_{1}$ - similarity index for the trees ' pollen group;

$\mathrm{SI}_{2}$ - the same for the shrubs' and small shrubs` pollen group;

$\mathrm{r}_{1-6}$ - the above-mentioned climatic elements reconstructed respectively.

The said formula (1) in our concrete case runs as follows:

$$
\mathrm{r}_{1-6}=\mathrm{R}_{1-6} \times \mathrm{SI}_{1} \text { or } \mathrm{SI}_{2}
$$

Naturally, the number of climatic elements during reconstructions in each concrete case can vary, which depends on concrete tasks solved by a researcher.

Introducing the above-mentioned climatic elements of the region-analog $\left(\mathrm{R}_{1}-\mathrm{R}_{6}\right)$ and similarity indices $\left(\mathrm{SI}_{1}, \mathrm{SI}_{2}\right)$ in formula (2), we shall obtain reconstructed climatic elements $-r_{1-6}$.

Below one can see the concrete calculation case.

Reconstruction of an average July temperature $\left(\mathrm{r}_{1}\right)$ and amounts of precipitation per annum $\left(\mathrm{r}_{5}\right)$ under $\mathrm{SI}_{1}$

$$
\begin{aligned}
& \mathrm{r}_{1}=\mathrm{R}_{1} \times \mathrm{SI}_{1} \\
& \mathrm{R}_{1}=12.3^{\circ} ; \mathrm{SI}_{1}=1.1 \\
& \mathrm{r}_{1}=12.3^{\circ} \times 1.1=13.5^{\circ} ; \\
& \mathrm{r}_{5}=\mathrm{R}_{5} \times \mathrm{SI}_{1} ; \\
& \mathrm{R}_{5}=837 \mathrm{~mm} ; \mathrm{SI}_{1}=1.1 ; \\
& \mathrm{r}_{5}=837 \mathrm{~mm} \times 1.1=920.7 \mathrm{~mm}
\end{aligned}
$$

Any climatic element can be calculated similarly.

Using data of Neishtadt and Tyulina [9], we have calculated the Similarity Indices for six components of pollen-spore spectra from the slope sediments of the Mayne River, a tributary of the Anadyr River, Betula,
Alnus, Abies, Pinus pumila, Larix, Salix. The calculated indices prove reliably the conclusions of scientists, which were made 100 years ago! This gives us a grounded confidence that the application of the similarity indices would allow excluding elements of subjectivism during paleogeographical reconstructions and correlations [10].

\section{Results and Discussions}

The above presented method of climate reconstruction with the use of similarity indices is developed with the help of the results of a concrete geological section study what is very important. This is a raised peat bog, $2.62 \mathrm{~m}$ thick, on the left bank of the Fomich River, south-east of the Taymyr Peninsula, Russia (71 $42^{\prime} \mathrm{N}, 108^{\circ} 03^{\prime}$ E) (Fig. 1).

By the quantitative characteristics of the climate and their dynamic in time, reconstructed for the Fomich River basin and for the Taymyr Peninsula, two types of climates have been established: tundra and forest (Fig. 3).

The tundra climate type fell on the time interval from $10500 \pm 140$ years BP $(10,650-10,275$ cal. years BP) till $7040 \pm 60$ years BP (5985-5841 cal. years BP) (for the pollen of trees group SI is equal to 0.26-0.31). This climate type dominated here during more than 3,500 years. It is notable of not so warm summer seasons as in the 20th century: $\mathrm{T}_{\mathrm{VII}}$ was $9.8-10.2{ }^{\circ} \mathrm{C}$ $\left(12.3^{\circ} \mathrm{C}\right)$ (hereinafter the contemporary climate's elements given in brackets); the sum of temperatures above $0{ }^{\circ} \mathrm{C}$ (hereinafter: $\Sigma \mathrm{T}_{\mathrm{VI}-\mathrm{IX}}$ ) within this period reached $670-695{ }^{\circ} \mathrm{C}\left(837{ }^{\circ} \mathrm{C}\right)$. The winter seasons were warmer than in the 20th century: $T_{I}$ was -27-28 ${ }^{\circ} \mathrm{C} \quad(-33.8)$; the average annual air temperatures were higher: $-10.7-11,2{ }^{\circ} \mathrm{C}\left(-13.4{ }^{\circ} \mathrm{C}\right)$; the annual amount of precipitation was smaller than in the 20th century, $58 \%$ of which fell out during the frost-free period. A cardinal change in the climate took place within the time interval 7,040-5,720 yrs BP: the tundra climate type was replaced by the forest climate 


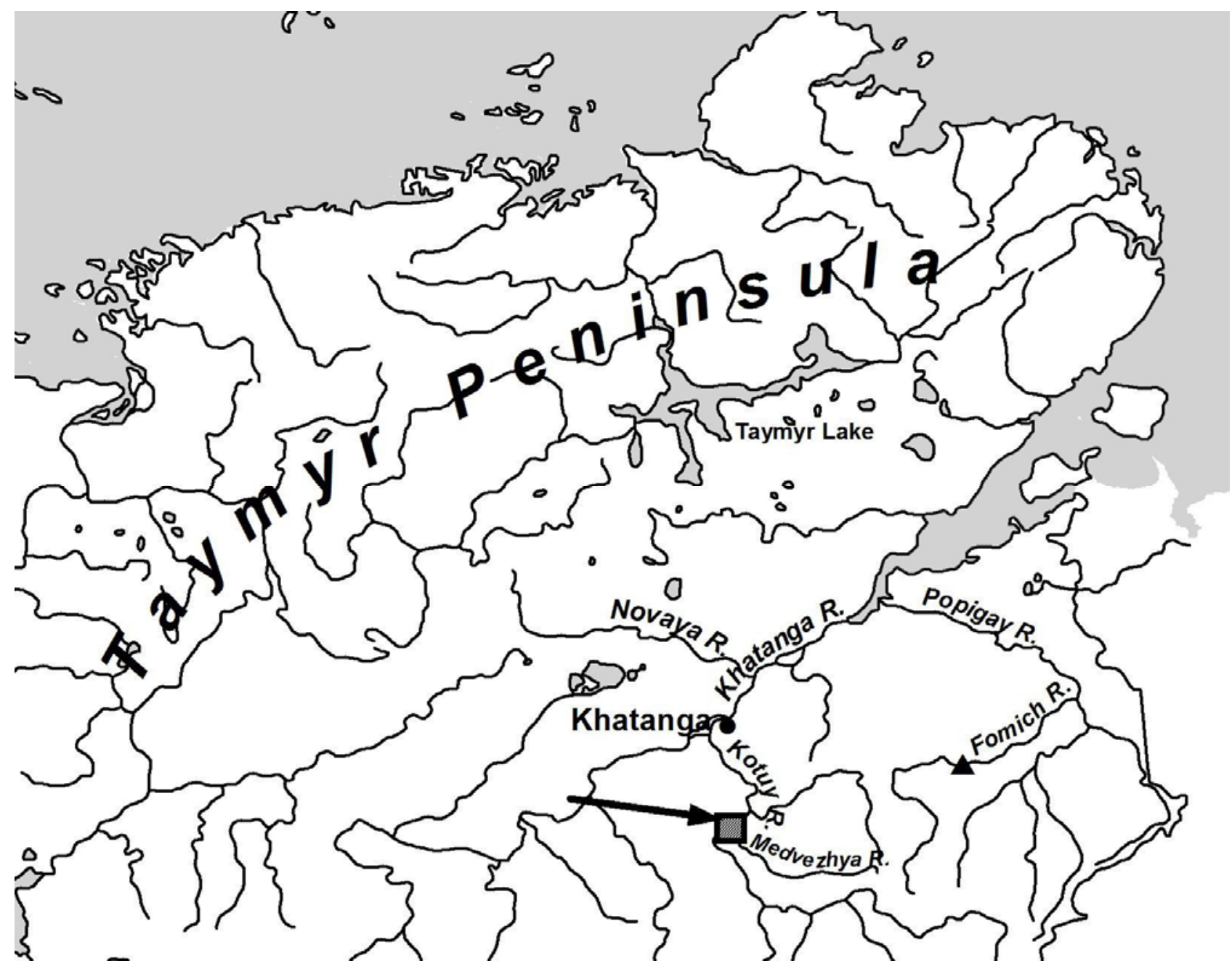

Fig. 1 Based on the data of the pollen-spore and radiocarbon methods during our research of the raised peat bog in the south-eastern part of the Taymyr Peninsula, we discovered for the first time the natural dynamic of the vegetation cover and climate for this region during the last $\mathbf{1 0 , 5 0 0}$ years. This raised peat bog was being formed during the entire Holocene. Its formation stopped $500 \pm 60$ yrs BP (1400-1470 AD), when it was overlapped with a sand layer. The peat bog was securely dated with seven radiocarbon date (Fig. 2).

type. This was reflected in the change of the vegetative cover: the tundra of the contemporary southern type with the presence of alder shrub Duschekia (Alnaster) fruticosa, which was dominating in this region almost 3,500 years (phytochrone $\mathrm{I}_{1-4}$ ), were replaced by larch forests formed by Gmelin larch Larix gmelinii (Rupr.) Rupr. (phytochrone $\mathrm{II}_{1-4}$, Fig. 2). Here we must emphasize the fact that Duschekia fruticosa is the powerful edificator of tundras of southern type.

The forest climate type fell on the time interval $5720 \pm 60$ yrs BP (4669-4463 cal. BP $)-500 \pm 60$ yrs
BP (1400-1470 years AD) - the present time (for the pollen of tree groups SI is equal to $0.9,-1.1,-1.0)$. The warmth and moisture availability within this time interval increased (Table 1). The summer seasons became warmer than the summer seasons $7040 \pm 60$ yrs BP and the summer seasons of the 20th century: $\mathrm{T}_{\mathrm{VII}-\mathrm{IX}}$ increased to $11.1-11.7^{\circ} \mathrm{C}$, maximum to $13.5^{\circ} \mathrm{C}$; the total of positive temperatures during the frost-free period increased to $595-753{ }^{\circ} \mathrm{C}$, maximum to $921{ }^{\circ} \mathrm{C}$. However, the winter seasons became colder than the winter seasons within the time interval of $10500 \pm 140$ yrs BP (10650-10275 cal. BP) $-7040 \pm 60$ yrs BP 


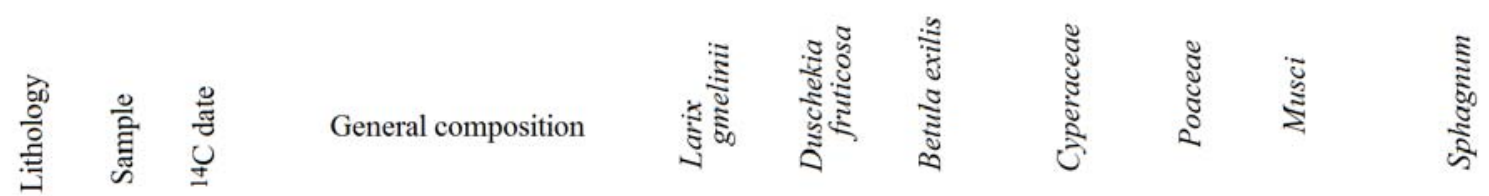

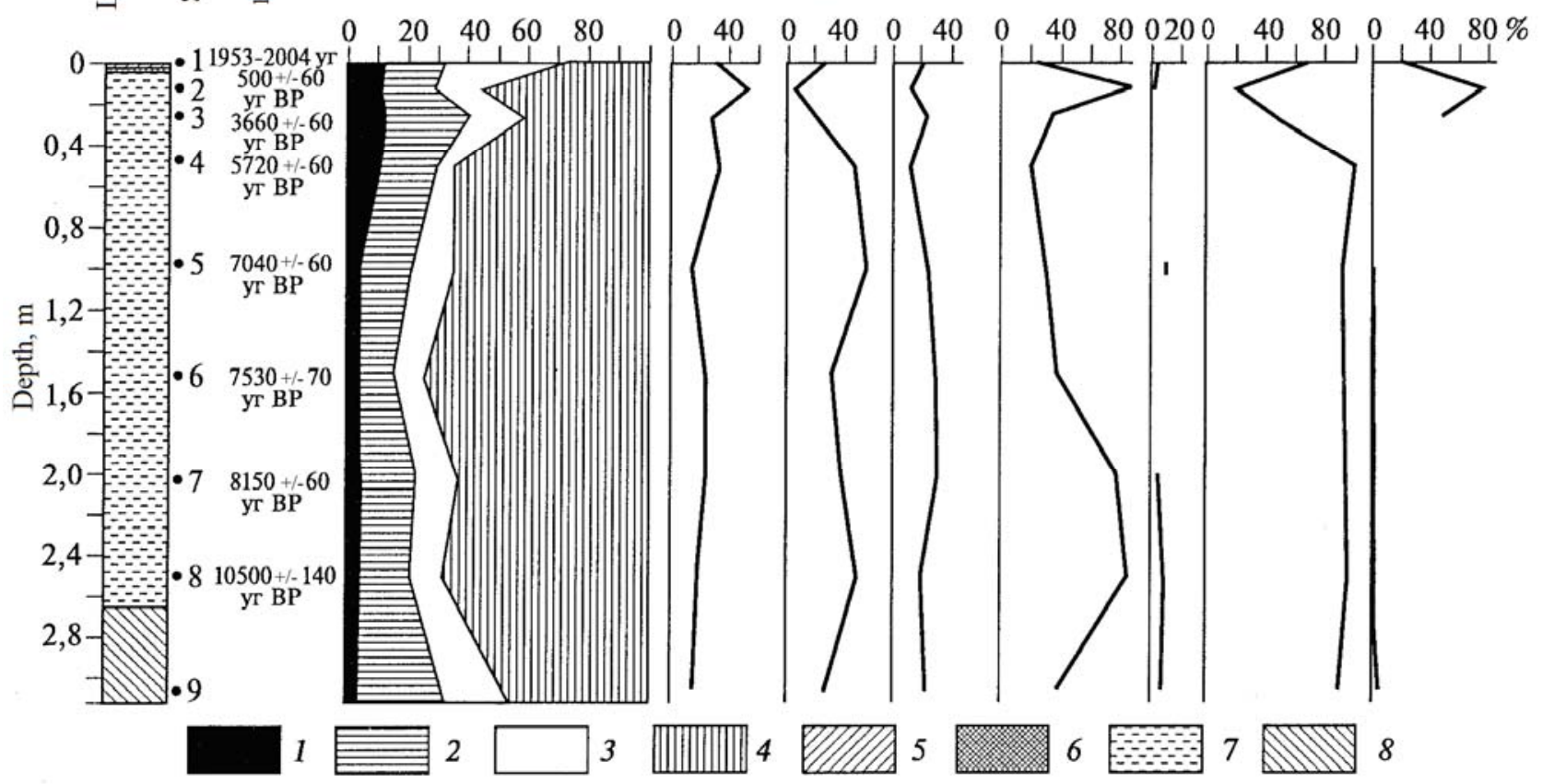

Fig. 2 Pollen-spore diagram for the sediments of the 2nd upper flood-land terrace of Fomich River, Taymyr Peninsula, Russia. Key: (1) pollen of trees; (2) pollen of shrubs and small hrubs; (3) pollen of grasses; (4) spores of mosses and ferns; (5) sand; (6) sand with organic matter included; (7) peat; (8) sand of mixed grain sizes.

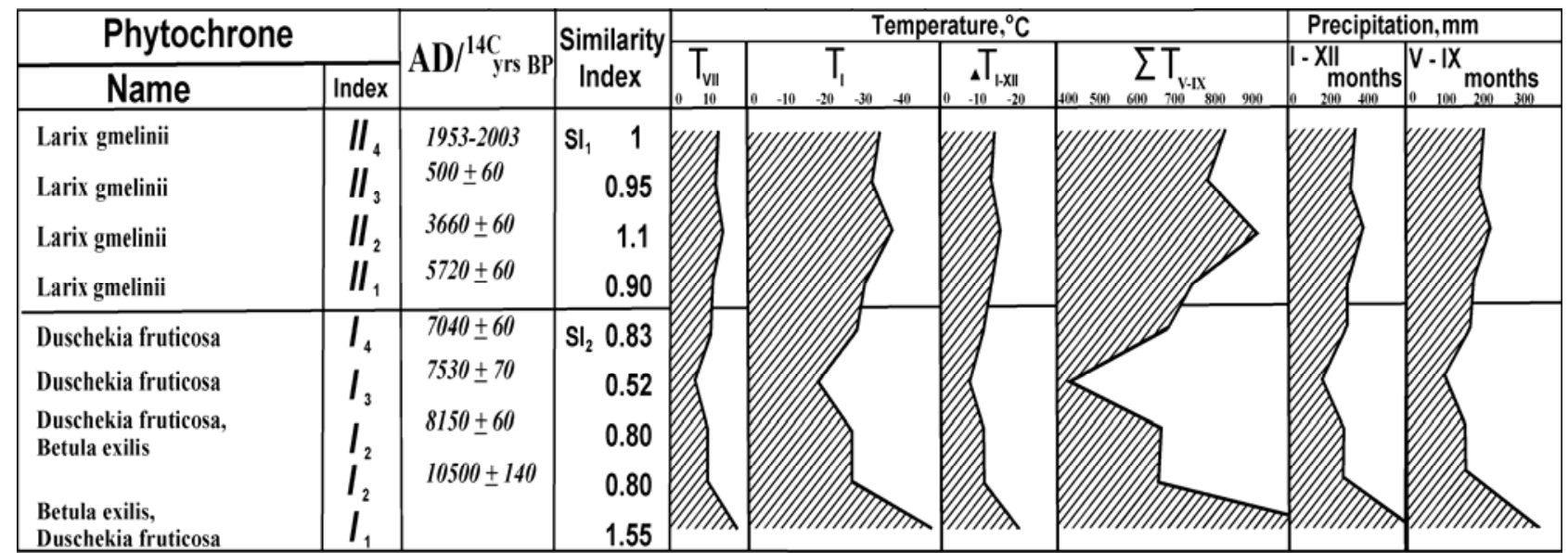

Fig. 3 Graphs, illustrating the character of warmth and precipitation availability in the basin of the Fomich River Basin, Taymyr Peninsula during the last 10,500 years or so.

(5985-5841 cal. BP); $\mathrm{T}_{\mathrm{I}}$ amounted to $-30,4,-37.2{ }^{\circ} \mathrm{C}$; the average annual temperature decreased to $-12.0-12.7{ }^{\circ} \mathrm{C}$, maximum to $-14.7^{\circ} \mathrm{C}$; the amount of precipitation per annum increased to $313-383 \mathrm{~mm}$, the most of it (58-62\%) falling out during the frost-free period. The above presented characteristics of the two climate types, the data of Table 1 and those of Figure 1 are evidence of the fact that in the first half of the Holocene (10500-7040 yrs BP) the climate in this region was stable enough (Table 1). Only $7530 \pm 70$ yrs BP a sharp cooling took place: the average air temperature in July was falling to $6.4{ }^{\circ} \mathrm{C}\left(+12.3{ }^{\circ} \mathrm{C}\right) ; \Sigma$ 
Table 2 Forecast of changes in the main climatic elements in the forthcoming 50 years for the high-latitude regions of Arctic. Note: In the brackets there are deviations of climatic elements from values of the 1950-2003 years.*) It's needed take into account that cycles of the Sun activity have duration from $81 \frac{1}{2}$ to 15 years $(10 ; 12)$.

\begin{tabular}{|c|c|c|c|c|c|c|}
\hline \multirow{3}{*}{$\frac{\text { Kupetskiy [ 10] }}{\text { Cycle Year Max W }}$} & \multicolumn{6}{|c|}{ Ukraintseva [9], Ukraintseva, Pospelov [5] } \\
\hline & \multirow[t]{2}{*}{ Years $(\mathrm{AD} / \mathrm{BP})$} & \multicolumn{5}{|c|}{ Element of Climate } \\
\hline & & $\mathrm{T}_{\mathrm{VII}}$ & $\mathrm{T}_{\mathrm{I}}$ & $\boldsymbol{\Delta} \mathrm{T}$ for year & Precipitation, Mм & SI \\
\hline 272048100 & 2048 & $(-0.6)$ & $(-1.7)$ & $(-0.7)$ & $(-36)$ & 0.95 \\
\hline 262036130 & 2036 & 12.3 & -33.8 & -13.4 & 348 & 1.0 \\
\hline 252024110 & 2024 & $(-0.6)$ & $(-1.7)$ & $(-0.7)$ & $(-36)$ & 0.95 \\
\hline 242012100 & 2014 & $(-0.6)$ & $(-1.7)$ & $(-0.7)$ & $(-36)$ & 0.95 \\
\hline \multirow[t]{8}{*}{$23 * 2000140$} & 2000 & 12.3 & -33.8 & -13.4 & 348 & 1.0 \\
\hline & $500 \pm 60$ & $11.7(-0.6)$ & $-32.1(-1.7)$ & $-12.7(-0.7)$ & $312(-36)$ & 0.95 \\
\hline & $3660 \pm 60$ & $13.5(+1.2)$ & $-37.2(+3.4)$ & $-14.7(+1.3)$ & $383(+35)$ & 1,1 \\
\hline & $5720 \pm 60$ & $11.1(-1,2)$ & $-30.4(-3.4)$ & $-12.0(-1.4)$ & $313(-35)$ & 0.9 \\
\hline & $7040 \pm 60$ & $10.2(-1.2)$ & $-28.0(-5.8)$ & $-11.2(-2,2)$ & $289(-69)$ & 0.83 \\
\hline & $7530 \pm 70$ & $6.4(-5.9)$ & $-17.6(-6.2)$ & $-7.1(-6.4)$ & $181(-167)$ & 0.52 \\
\hline & $8150 \pm 60$ & $9.8(-2.5)$ & $-27.0(-6.8)$ & $-10.7(-2.7)$ & $278(-70)$ & 0.80 \\
\hline & $10500 \pm 60$ & $9.8(-2.5)$ & $-27.0(-6.8)$ & $-10.7(-2.7)$ & $278(-70)$ & 0.80 \\
\hline
\end{tabular}

$\mathrm{T}_{\mathrm{VIIIX}}$ fell to $435{ }^{\circ} \mathrm{C}\left(837{ }^{\circ} \mathrm{C}\right)$; however, the winter temperatures were considerably higher than in the 20th century: $\mathrm{T}_{\mathrm{I}}$ reached $-17.6{ }^{\circ} \mathrm{C}\left(-33.8{ }^{\circ} \mathrm{C}\right)$; the average annual temperature was rising up to $-7.0^{\circ} \mathrm{C}$ $\left(-13.4{ }^{\circ} \mathrm{C}\right)$. However, already $7040 \pm 60 \mathrm{yrs}$ BP, i.e. 490 years later, the climatic condition, which was here before the cooling, practically restored itself. The summer seasons during the first half of the Holocene were not as warm as the summer seasons of the 20th century, whereas the winter seasons were warmer than the winter seasons of the 20th century. The deviations for all reconstructed elements are negative in comparison with the climatic elements of the 20th century. The climate of the second half of the Holocene, starting with $5720 \pm 60 \mathrm{yrs} \mathrm{BP}$ and up to the present time, is notable for its alternating fluctuations.

The suggested new method does not only allow to reconstruct of elements of climates of the past and their deviations in comparison with today's elements, but also allows making a forecast of climate changes in the future on the regional level, as well as using the obtained data for a forecast of climate changes in the future on the global level.

Taking into account the data of reconstruction of climate only as a basis, we can talk about of a trend of climatic changes in the future only. However, compare the Sun activity forecast expressed in Wolf units (Max W, Min W) made by Kupetsky [10], with the climatic characteristics which have been reconstructed by us (Table 2), we could make then a more precise forecast of climatic changes for the Taymyr Peninsula and for the Russian part of Arctic.

\section{Conclusion}

The above forecast lets us to make the following basically important conclusions.

(1) The climate's warming, which is currently being observed on the Earth (the 23rd cycle of the Sun's activity) will last till 2014 or so;

(2) During the following two cycles (24th and 25th) the Sun's activity will decrease to 100-110 Wolf units, which will cause a cooling of the climate on the Earth;

(3) In the following, the 26th cycle, the Sun's activity will increase up to 130 Wolf units, which will cause a warming of the climate again;

(4) In the 27th cycle (2037-2048 years) the Sun's activity will decrease to 100 Wolf units, causing a cooling on the Earth again. 
Thus, the forecast of climatic changes in the Arctic, which we have worked based on the Sun's-Earth's connections, is an objective natural reality. It is safe to say, the climate fluctuations in the Arctic, which we have identified for the last 12-10 thousand years, will continue in the forthcoming 50-100 years. Consequently, only the synthesis of solar-telescopic data, paleoclimate data and modern meteorological data allow making a valid long-term global forecast of climatic changes in the future. Regional and local forecasts will be then of the primary value. The level of contemporary scientific knowledge does not show us any other way yet. This forecast is needed to be taken into consideration in management plans. Our results give ground scientific basis for climatic management and policy support.

In conclusion, a wealth of paleoecological data have been obtained from peat archives across the Globe, and one of the remaining challenges is now to interpret these data in term of quantitative past climate and environment changes and use the obtained data for the forecasts of climatic changes on the Earth.

Data of this paper have been offered to the 2nd PAGES Workshop: Constraining Solar Forcing by "Detection and Attribution" for the Holocene, 20-23 May 2014, Davos, Switzerland.

Author would like to thank the editor for inviting to contribute this paper as well as for valuable support and patience. Thank a lot to peer reviewers.

\section{References}

[1] ACIA. 2005. Impacts of a Warming Climate: Arctic Climate Impact Assessment. Cambridge: Cambridge University Press.

[2] Faegri, K., and Iversen, J. 1989. Text-book of Modern
Pollen Analysis, 4th ed. Chichester: Wiley.

[3] Grichuk, V. P., and Zaklinskaya, E. D. 1948. Analysis of Fossil Pollen and Spores and Use of It in Paleogeography. Moscow: State Publishing Office of Geographical Literature. (Russian)

[4] Tuhkanen, S. 1980. Climatic Paramenters and Indices in Plant Geography. Acta Phytogeogr. Suecica 67: 1-105. Upsala: Science.

[5] Ukraintseva, V. V., and Pospelov, I. N. 2005. "The First Data on the History and Evolution of Vegetation and Climate in the Northern Part of the Anabar Plateau in the Holocene." In Modern Problems of Palaeofloristics, Palaeophytogeography and Phytostratigraphy, Transaction of the International Paleobotanical Conference, Moscow, 319-24.

[6] Ukraintseva, V. V., and Pospelov, I. N. 2012. "About of A New Integrated Methods of Reconstruction of Climates and Forecasting of Climatic Changes in Future." Society Environment Development 2: 203-12 and 3: 216-22. (Russian)

[7] Borisov, A. A. 1975. Climate of the USSR in the Past, Present and Future. Leningrad: Izdatel'stvo LGU. (Russian)

[8] Grichuk, V. P. 1969. "Experience of Reconstruction of Some Elements of Climate of the Northern Hemisphere in Atlantic Time of the Holocene." Edited by Neishtadt, M. I. The Holocene. Moscow: Nauka, 41-57. (Russian)

[9] Ukraintseva, V. V. 2005. "Use of the Index of Similarity for the Assessment of Fossil Spore-Pollen Spectra." In Modern Problems of Palaeofloristics, Palaeophytogeography and Phytostratigraphy, Transaction of the International Paleobotanical Conference, Vol. 1, pp. 314-8.

[10] Kupetsky, V. N. 1988. "Landscapes of the Freezing Seas." Ph.D. thesis, Saint-Petersburg State University, Saint-Petersburg. (Russian)

[11] Reference Book on the Climate of the USSR. 1967. Issue 25, part 2. (Russian)

[12] Lockwood, M. 2013. "Reconstruction and Prediction of Variations in the Open Solar Magnetic Flax and Interplanetary Conditions.” Living Rev. Solar Phys. 10: 4. 